\title{
Regular exercise and behavioural management by caregivers improves physical and mental health of people with Alzheimer's disease
}

Teri L, Gibbons LE, McCurry SM, et al. Exercise plus behavioral management in patients with Alzheimer disease. JAMA 2003;290:2015-22.

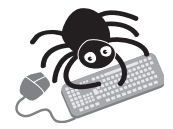

This article contains extra text on the EBMH website

Does an exercise programme for people with Alzheimer's disease, plus behavioural management by a trained family member, improve mental and physical health compared with routine care?

METHODS

$\square$

Design: Randomised controlled trial.

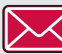

Allocation: Concealed.

Blinding: Assessors blinded to treatment.

Follow up period: Twenty four months.

Setting: Seattle, USA; June 1994 to April 1999

Patients: 153 people (mean age 78 years, range 55-93 years; $59 \%$ male) with moderate to severe Alzheimer's disease, living in the community, with a caregiver willing to participate in the study.

R

Intervention: Three month exercise programme or usual care.

The exercise programme consisted of 12 one hour sessions conducted at the participant's home, by a healthcare professional, with the aim of promoting at least 30 minutes of moderate exercise per day. In addition, caregivers were educated about dementia, trained to recognise and resolve behavioural problems, and encouraged to increase social and physical activities. Usual care included short term medical treatment and crisis management intervention by healthcare professionals or community services.

国要

Outcomes: Physical health and function (SF-36, Sickness Impact Profile (SIP)); affective status (Cornell Scale for Depression in Dementia (CSDD)) and amount of exercise per week.

Patient follow up: Exercise programme: $45 / 76$ (59\%) up to 24 months; usual care: $44 / 77$ (57\%) up to 24 months.

\section{MAIN RESULTS}

Analysis was by intention to treat. The percentage of participants exercising $\geqslant 60$ minutes per week increased in the exercise group compared with usual care $(82 \% v 62 \%, \mathrm{p}=0.01)$ at 3 months follow up. Exercise improved levels of physical functioning (SF-36 score, $\mathrm{p}<0.001$ ) and depression (CSDD, $\mathrm{p}=0.02$ ) compared with usual care (whose levels worsened) at 3 months follow up. At 24 months, longitudinal analyses of all follow up data revealed improvements in exercise group mobility (SIP, $\mathrm{p}=0.02$ ) and physical functioning

For correspondence: $\operatorname{Dr}$ L Teri, Psychosocial and Community Heälth University of Washington, Seattle, USA. Iteri@u.washington.edu

Sources of funding: The National Institute on Aging.
$($ SF-36, $\mathrm{p}<0.01$ ) and but not depression (CSDD, $\mathrm{p}=0.10)$, compared with usual care (see web extra table).

\section{CONCLUSIONS}

For people with Alzheimer's disease, daily moderate intensity exercise combined with behavioural management by a trained family member improves physical and mental health.

\section{Commentary}

Ithough the cognitive, functional, and behavioural decline of Alzheimer's disease are well recognised, the associated general physical deterioration that occurs has received far less attention. Physical activity may improve physical condition, cardiovascular function, depression, and function. Further, training caregivers to be therapists for persons with dementia can reduce patient depression and delay institutionalisation. ${ }^{12}$

This randomised controlled trial examines whether a home based exercise programme combined with caregiver training in behavioural management techniques would, in comparison with routine medical care, improve depression and physical frailty in people with Alzheimer's disease. They were community dwelling patients with moderately severe Alzheimer's disease (average MMSE score 16.8, aged 55-93 years). Caregivers were mostly white, female, and spouses.

The study is novel in that it focuses on a different aspect of training caregivers from what has been done before. 'Although the title of the paper emphasises exercise and behaviour management, the intervention included much more. Patient caregivers were seen in their own homes for 12 hour long sessions, twice weekly for the first three weeks, then weekly for four weeks, and then second weekly for the last four weeks; and for follow up, three times over the next three months. Caregivers were taught to identify problem behaviours and given specific instructions on how to reduce them. They received education about dementia, the use of pleasant activities, and ways of increasing physical and social activity.

As regards generalisability, the study requires replication and clinicians would need access to a comprehensive support programme. Structured interventions such as this do exist loften through local Alzheimer's associations) but they are scattered and not available in a comprehensive, systematic manner.

The authors acknowledge that it is not possible to know which elements of their programme are effective. Indeed it may not be that any particular elements are specifically effective but the provision of a comprehensive, structured programme involving carers and patients is what matters most. $^{2}$

The paper is well written, methodologically sound, statistically well analysed and provides further evidence of the importance of working with family caregivers once a diagnosis of dementia is made. Henry Brodaty, MD University of New South Wales, Sydney, Australia

1 Brodaty H, Gresham M. Effect of a training programme to reduce stress in carers of patients with dementia. BMJ 1989:299:1375-9.

2 Brodaty H, Green A, Koschera A. Meta-analysis of psychosocial interventions for caregivers of people with dementia. J Am Geriatric Soc 2003;51:657-64. 